\title{
CHA2DS2-VASC SCORE AS A PREDICTOR FOR CONTRAST-INDUCED NEPHROPATHY IN PATIENT WITH ISCHEMIC HEART DISEASE TREATED WITH PERCUTANEOUS CORONARY INTERVENTION
}

\author{
By
Islam S. Abd-Allah, Osama A. Khamis *, Mostafa A. Al-Sawasany and Ebrahim F. Said \\ Departments of Cardiology and Medicine*, Faculty of Medicine, Al-Azhar University \\ *Corresponding Author: Islam Shehata Abd-Allah,
}

Mobile: 01013855599, E-mail: islamshehata227@gmail.com

\begin{abstract}
Background: CHA2DS2-VASC risk score (CVRS) is useful in predicting the occurrence of contrast induced nephropathy (CIN) among patients with Ischemic heart disease undergoing percutaneous coronary Intervention. CIN was defined an absolute increase in serum creatinine levels by $\geq 0.3 \mathrm{mg} / \mathrm{dL}$ from baseline, or a relative increase in serum creatinine by $\geq 50 \%$ from baseline, within $48 \mathrm{~h}$ after PCI, according to Acute kidney Injury Network (AKIN) definition.
\end{abstract}

Objective: To evaluate CHA2DS2-VASC score as a predictor of contrast induced nephropathy (CIN) in patient with ischemic heart disease undergoing percutaneous coronary intervention (PCI).

Patients and Methods: A total of 200 consecutive patients presenting to Cardiology Department, Almogama Alteby Hospital at Tanta city ,during the period from January 2019 to January 2020, diagnosed as IHD and underwent PCI, They were divided into two groups: Group I: Those who developed CIN $48 \mathrm{~h}$ after PCI (28\%) and Group II: Those who did not (72\%). CHA2DS2-VASc score (age, sex, diabetes, hypertension, heart failure on admission, previous ischemic event, vascular event) was calculated for each patient. Serum creatinine level and estimated Glomerular Filtration Rate (eGFR) were estimated for all patient before and $48 \mathrm{~h}$ after PCI.

Results: CIN was reported in 56 patients (28\%). Patients with CIN had a higher frequency of hypertension, diabetes mellitus, and had a lower left ventricular ejection fraction and baseline estimated glomerular filtration rate. The average CVRS in the CIN group was significantly higher than that in non-CIN group. CHADSVASC score cut off value was higher than 3 and the area under the ROC curve was equal to 0.906 which indicating that it is excellent predictor for contrast induced nephropathy cases. The sensitivity, Specificity, positive predictive value and negative predictive values of CHADSVASC score were 80.36, $89.58,51.5$, and 96.0 respectively.

Conclusion: The CVRS can be used as a simple pre-procedural predictor of CIN among patients with IHD undergoing PCI.

Keywords: IHD, CHA2DS2-VASc score, contrast-Induced Nephropathy, Percutaneous Coronary Intervention. 


\section{INTRODUCTION}

The CHA2DS2-VASC (Congestive heart failure or left ventricular dysfunction, Hypertension, Age $\geq 75$ years, Diabetes Mellitus, Previous stroke, Vascular disease, Age between (65-74) years, female gender) score was designed to determine the thromboembolic risk and oral anti-coagulant therapy in nonvalvular atrial fibrillation (Lip et al., 2010). However, it was recognized to also be useful in the prediction of severity of coronary artery disease and coronary artery disease-related mortality due to the presence of some common risk factors (Bozbay et al., 2017).

It may also be used for prediction of mortality and morbidity in congestive heart failure patient who are candidates for cardiac resynchronization treatment (Paoletti Perini et al., 2014).

It was revealed to be predictor for thrombus and embolism, even in patient who don't have atrial fibrillation or who have supraventricular arrhythmia (Liu et al., 2016).

The reported incidence of CIN varies widely in different populations, ranging from $7 \%$ to $25 \%$, depending on the presence of risk factors. Hence, risk stratification is important, in order to apply the appropriate extent of prophylactic strategy in high -risk population (Brar et al., 2018).

Studies have revealed many predictors for contrast induced nephropathy after PCI, such as red cell distribution width, platelet to lymphocyte ratio, ACEF score (age, glomerular fraction, ejection fraction), mehran score, one of these predictors is the CHA2DS2 VASC score (Hudzik et al.,2016).

We aimed in this study to evaluate CHA2DS2-VASC as a predictor for contrast induced nephropathy in patient with ischemic heart disease treated with percutaneous coronary intervention.

\section{PATIENTS AND METHODS}

A total of 200 consecutive patients presenting to cardiology department, Almogama Alteby Hospital at Tanta city diagnosed as IHD and undergoing PCI were initially enrolled between January 2019 and January 2020 (12month).

These patients with IHD ((1.acute coronary syndrome (ACS): comprised both ST elevation myocardial infarction (STEMI) and non ST-elevation ACS subgroups who were planned for PCI, 2.chronic coronary syndrome (CCS) who diagnosed with coronary angiography and were planned for PCI.))

Patients were diagnosed based on history, physical examination findings, electrocardiographic criteria, cardiac biomarkers, echocardiographic imaging and coronary angiography.

The exclusion criteria included: patients with an estimated glomerular filtration rate (eGFR) < 15 $\mathrm{mL} / \mathrm{min} / 1.73 \mathrm{~m} 2$, either with or without preexisting dialysis, hematological disorders, with active hepato-biliary disease, with active infections, recent exposure to radiographic contrast media (within 10 days of enrollment),Patients who died during or early after procedure or lack of data on serum creatinine during the $48 \mathrm{~h}$ after the procedure were excluded from the study. 
Venous blood sample had been obtained on admission from each patient in the coronary care unit before PCI. Serum creatinine and serum urea levels were determined at the time of admission, daily up to $48 \mathrm{~h}$ after PCI.

Estimated glomerular filtration rate (eGFR) before, and patients with eGFR (60-15) $\mathrm{mL} / \mathrm{min}$ will undergo preparation.

GFR had been calculated by the abbreviated MDRD equation: GFR $\left(\mathrm{mL} / \mathrm{min} / 1.73 \quad \mathrm{~m}^{2}\right)=175 \times$ $(\mathrm{Scr} / 88.4) 1.154 \times($ Age $) 0.203 \times(0.742$ if female) $\times(1.212$ if African American) (SI units) (Levey et al., 2011).

Baseline investigations included complete blood counts, fasting and post prandial plasma sugar levels, glycated hemoglobin, and fasting lipid profiles. Left ventricular ejection fraction (LVEF) was estimated by $2 \mathrm{D}$ echocardiography at admission using Simpson's method. Wall motion score will be assessed in a 17segment model. Segmental wall motion will be judged as normal $=1$, hypokinetic $=2, \quad$ akinetic $=3, \quad$ and dyskinetic $=4$. The index (WMSI) is calculated by dividing the total of the wall motion scores of each segment by 17 .

CHA2DS2-VASc score was calculated for each patient by giving a score of 1 to each of these variables: (i) $\mathrm{CHF}$ or left ventricular systolic dysfunction $\mathrm{EF}$ $40 \%$,(ii) hypertension, (iii) age 65-74 years, (iv) diabetes mellitus, (v) vascular disease, and (vi) female gender and 2 points for (vii) age 75 years or older, and (viii) previous stroke or transient ischemic attack each. All PCI procedures were performed by experienced interventional cardiologists either through the Trans femoral or Trans radial approach depending on the expertise and technical feasibility. Nonionic, low-osmolar contrast (Iohexol, omnipaque $350 \mathrm{mg} / \mathrm{mL}$ ) were used during PCI. Patients with GFR $<60 \mathrm{ml} / \mathrm{min} / 1.73 \mathrm{~m} 2$ received intravenous hydration with standard normal saline at rate $1 \mathrm{ml} / \mathrm{kg} / \mathrm{hr}$ ( or $0.5 \mathrm{ml} / \mathrm{kg} / \mathrm{hr}$ in patients with heart failure) Nephrotoxic drugs such as metformin and non-steroidal antiinflammatory drugs were withdrawn before PCI. All patients were pretreated with aspirin (300mg) and a P2Y12 antagonist (clopidogrel $600 \mathrm{mg}$ or ticagrelor $180 \mathrm{mg}$ ) before PCI. In addition, unfractionated heparin in a dose of 70-100 $\mathrm{U} / \mathrm{kg}$ was administered during the procedure. The use of glycoprotein $\mathrm{IIb} / \mathrm{III}$ inhibitors during and after PCI was at the operator's discretion. TIMI (Thrombolysis in Myocardial Infarction) blood flow grade: Reperfusion will be considered successful (TIMI 3) or abnormal (TIMI 0-1-2).

TIMI 0 flow (no perfusion) refered to the absence of any antegrade flow beyond a coronary occlusion.

TIMI 1 flow (penetration without perfusion) was faint antegrade coronary flow beyond the occlusion, with incomplete filling of the distal coronary bed.

TIMI 2 flow (partial reperfusion) was delayed or sluggish ante grade flow with complete filling of the distal territory.

TIMI 3 flow was normal flow which filled the distal coronary bed completely.

\section{Statistical Analysis:}

Data were collected throughout history, basic clinical examination; laboratory investigations and outcome measures 
coded, entered and analyzed using Microsoft Excel software.

The data collected were tabulated and analyzed by SPSS (statistical package for the social science) version 25 (IBM, Armonk, NY, USA) on IBM compatible computer. Two types of statistics were done:

\section{Descriptive statistics:}

Qualitative data were represented as number and percentage, while quantitative data are represented by mean \pm SD.

\section{Analytic statistics:}

-Chi-square test $\left(\chi^{2}\right)$ and Fisher Exact test: was used to study comparison and association between two qualitative variables.

- Independent samples Student t-test: is a test of significance used for comparison between two groups having quantitative variables with normal distribution (control and pre or post).

- Mann-Whitney U Test: is a test of significance used for comparison between two groups having quantitative variables without normal distribution (for non-parametric data).

- A P-value of $<0.05$ was considered statistically significant.

- A receiver operating characteristic curve or ROC curve was used to show the connection between the clinical sensitivity and specificity for cut-off value. In addition the area under the ROC curve gave an idea about the benefit of using the score.

\section{RESULTS}

A total of 200 patients with IHD (136 males, $68.0 \%$ ) having a mean age of 60.01 \pm 10.84 years were enrolled in this study.

Chronic coronary syndrome (ccs) was the most frequent clinical diagnosis in $100 / 200(50 \%)$ patients, followed by STEMI 50/200(25\%) and NSTE-ACS $50 / 200(25 \%)$. The mean CHA2DS2VASc score in the study population was $2.68 \pm 1.39$.CIN occurred in 56/200 (28\%) patients after PCI. Based on the presence or absence of CIN, the enrolled participants were divided into Group1 (CIN) and Group 2 (no CIN).

Patients in Group1 (CIN subgroup) were older $(67.80 \pm 8.90$ vs. $56.98 \pm 10.0$, p-value <0.001) and had significantly higher number of hypertensive and diabetics as compared with group 2. In addition, a higher number of patients in Group 1 had previous history of CAD, cerebro vascular accidents. Incidence of CIN in patients of ACS was higher than in patients of $\mathrm{CCS}(31 \%$ and $25 \%$ respectively). CHADS-VASC score and in hospital stay (days) Mean \pm SD were $(4.16 \pm 1.02)$ and $(5.30 \pm 1.8)$ in the CIN positive group and were $(2.10 \pm 1.05)$ and $(2.71 \pm 0.98)$ in the CIN negative group CHADSVASC score and in hospital stay were statistically significant higher in the CIN positive group. There was no statistically significant difference between the two groups as regards the gender, smoking, hyperlipidemia, previous CABAG and weight (Table 1). 
CHA2DS2-VASC SCORE AS A PREDICTOR FOR CONTRAST...

Table (1): Demographic data of the two study groups

\begin{tabular}{|c|c|c|c|c|c|c|c|}
\hline \multirow{3}{*}{$\begin{array}{c}\text { Groups } \\
\text { Parameters }\end{array}$} & \multirow{2}{*}{\multicolumn{2}{|c|}{$\begin{array}{c}\text { Total } \\
(\mathbf{n}=\mathbf{2 0 0})\end{array}$}} & \multicolumn{4}{|c|}{ CIN } & \multirow{3}{*}{$\mathbf{P}$} \\
\hline & & & \multicolumn{2}{|c|}{ No $(n=144)$} & \multicolumn{2}{|c|}{ Yes $(n=56)$} & \\
\hline & No. & $\%$ & No. & $\%$ & No. & $\%$ & \\
\hline \multicolumn{8}{|l|}{ Sex } \\
\hline Female & 64 & 32.0 & 43 & 29.9 & 21 & 37.5 & \multirow{2}{*}{$>0.05$} \\
\hline Male & 136 & 68.0 & 101 & 70.1 & 35 & 62.5 & \\
\hline \multicolumn{8}{|l|}{ Age(years) } \\
\hline Min. - Max. & \multicolumn{2}{|c|}{$34.0-85.0$} & \multicolumn{2}{|c|}{$34.0-80.0$} & \multicolumn{2}{|c|}{$43.0-85.0$} & \multirow{2}{*}{$<0.001$} \\
\hline Mean \pm SD & \multicolumn{2}{|c|}{$60.01 \pm 10.84$} & \multicolumn{2}{|c|}{$56.98 \pm 10.0$} & \multicolumn{2}{|c|}{$67.80 \pm 8.90$} & \\
\hline DM & 115 & 57.5 & 72 & 50.0 & 43 & 76.8 & 0.001 \\
\hline HTN & 110 & 55.0 & 67 & 46.5 & 43 & 76.8 & $<0.001$ \\
\hline Smoking & 94 & 47.0 & 66 & 45.8 & 28 & 50.0 & $>0.05$ \\
\hline Hyperlipidemic & 159 & 79.5 & 116 & 80.6 & 43 & 76.8 & $>0.05$ \\
\hline \multicolumn{8}{|l|}{ Weight } \\
\hline Min. - Max. & \multirow{2}{*}{\multicolumn{2}{|c|}{$\begin{array}{c}69.0-130.0 \\
90.17 \pm 10.07\end{array}$}} & \multirow{2}{*}{\multicolumn{2}{|c|}{$\begin{array}{c}69.0-130.0 \\
89.92 \pm 10.08\end{array}$}} & \multirow{2}{*}{\multicolumn{2}{|c|}{$\begin{array}{c}74.0-120.0 \\
90.80+10.11\end{array}$}} & \multirow{2}{*}{$>0.05$} \\
\hline Mean \pm SD. & & & & & & & \\
\hline CVA & 11 & 5.5 & 5 & 3.5 & 6 & 10.7 & $>0.05$ \\
\hline Vascular event & 46 & 23.0 & 22 & 15.3 & 24 & 42.9 & $<0.001$ \\
\hline Previous CABG & 5 & 2.5 & 2 & 1.4 & 3 & 5.4 & $>0.05$ \\
\hline Nephrotoxic drugs & 61 & 30.7 & 38 & 26.4 & 23 & 41.8 & $<0.05$ \\
\hline \multicolumn{8}{|l|}{ Presentation } \\
\hline \multicolumn{8}{|l|}{ STEMI } \\
\hline Anterior & 20 & 10.0 & 17 & 11.8 & 3 & 5.4 & $>0.05$ \\
\hline Ex. Anterior & 14 & 7.0 & 12 & 8.3 & 2 & 3.6 & $>0.05$ \\
\hline Anterior + Inferior & 3 & 1.5 & 0 & 0.0 & 3 & 5.4 & $<0.05$ \\
\hline Inferior + Posterior & 3 & 1.5 & 1 & 0.7 & 2 & 3.6 & $>0.05$ \\
\hline Inferior + RT & 6 & 3.0 & 2 & 1.4 & 4 & 7.1 & $>0.05$ \\
\hline Inferior, RT, Posterior & 3 & 1.5 & 1 & 0.7 & 2 & 3.6 & $>0.05$ \\
\hline $\begin{array}{c}\text { Inferior + Posterior } \\
\text { +Lateral }\end{array}$ & 1 & 0.5 & 1 & 0.7 & 0 & 0.0 & $>0.05$ \\
\hline NSTE-ACS & 50 & 25.0 & 35 & 24.3 & 15 & 26.8 & $>0.05$ \\
\hline CCS & 100 & 50.0 & 75 & 52.1 & 25 & 44.6 & $>0.05$ \\
\hline $\begin{array}{c}\text { CHA2DS2-VASC score } \\
\text { Min-Max } \\
\text { Mean } \pm \text { SD }\end{array}$ & \multicolumn{2}{|c|}{$\begin{array}{c}0.0-6.0 \\
2.68 \pm 1.39\end{array}$} & \multicolumn{2}{|c|}{$\begin{array}{c}0.0-5.0 \\
2.10 \pm 1.05\end{array}$} & \multicolumn{2}{|c|}{$\begin{array}{c}1.0-6-0 \\
4.16 \pm 1.02\end{array}$} & $<0.001$ \\
\hline $\begin{array}{c}\text { In hospital stay(days) } \\
\text { Min-Max } \\
\text { Mean SD }\end{array}$ & \multicolumn{2}{|c|}{$\begin{array}{c}1.0-11.0 \\
3.44 \pm 1.74\end{array}$} & \multicolumn{2}{|c|}{$\begin{array}{c}1.0-7.0 \\
2.71 \pm 0.98\end{array}$} & \multicolumn{2}{|c|}{$\begin{array}{c}2.0-11.0 \\
5.30 \pm 1.87\end{array}$} & $<0.001$ \\
\hline
\end{tabular}

The WMSI Mean \pm SD $(1.71 \pm 0.48)$ and $(1.41 \pm 0.39)$ (in the CIN positive and negative groups respectively statistically significant higher in the CIN positive group. The Cr before Mean \pm SD was (1.1 $\pm 0.23)$ and $(0.97 \pm 0.21)$ in the CIN positive and negative groups respectively statistically significant higher in the CIN positive group. The GFR before Mean \pm
SD was $(75.27 \pm 21.52)$ and $(85.31 \pm$ 22.33) in the CIN positive and negative groups respectively statistically significant lower in the CIN positive group. HF before was more relevant in the CIN positive group was $53.6 \%$ statistically significantly higher than the CIN negative group where it was $9.7 \%$ (Table 2). 
Table (2): Clinical and laboratory findings in the two studied groups

\begin{tabular}{|c|c|c|c|c|c|c|c|}
\hline \multirow{3}{*}{$\begin{array}{c}\text { Groups } \\
\text { Parameters }\end{array}$} & \multirow{2}{*}{\multicolumn{2}{|c|}{$\begin{array}{c}\text { Total } \\
(\mathbf{n}=\mathbf{2 0 0})\end{array}$}} & \multicolumn{4}{|c|}{ CIN } & \multirow{3}{*}{$\mathbf{P}$} \\
\hline & & & \multicolumn{2}{|c|}{ No $(n=144)$} & \multicolumn{2}{|c|}{ Yes $(n=56)$} & \\
\hline & No. & $\%$ & No. & $\%$ & No. & $\%$ & \\
\hline $\begin{array}{c}\text { EF by simpson } \\
\text { method } \\
\text { Min-Max } \\
\text { Mean SD } \\
\end{array}$ & \multicolumn{2}{|c|}{$\begin{array}{c}30.0-68.0 \\
50.08 \pm 9.68\end{array}$} & \multicolumn{2}{|c|}{$\begin{array}{c}33.0-67.0 \\
51.83+8.25\end{array}$} & \multicolumn{2}{|c|}{$\begin{array}{c}30.0-68.0 \\
45.57 \pm 11.55\end{array}$} & $<0.001$ \\
\hline \multicolumn{8}{|c|}{ Wall motion score index (WMSI) } \\
\hline Min. - Max. & \multirow{2}{*}{\multicolumn{2}{|c|}{$\begin{array}{c}1.0-2.50 \\
1.49 \pm 0.43\end{array}$}} & 1.0 & -2.50 & 1.0 & -2.50 & \multirow{2}{*}{$<0.001$} \\
\hline Mean \pm SD & & & 1.41 & 0.39 & 1.7 & 0.48 & \\
\hline $\begin{array}{c}\text { Systolic blood } \\
\text { pressure }\end{array}$ & \multicolumn{2}{|c|}{$(n=199)$} & \multicolumn{2}{|c|}{$(n=144)$} & \multicolumn{2}{|c|}{$(\mathrm{n}=55)$} & \\
\hline Min. - Max. & \multirow{2}{*}{\multicolumn{2}{|c|}{$\begin{array}{c}70.0-200.0 \\
130.4 \pm 23.01\end{array}$}} & \multicolumn{2}{|c|}{$90.0-180.0$} & \multicolumn{2}{|c|}{$70.0-200.0$} & \multirow{2}{*}{$>0.05$} \\
\hline Mean \pm SD. & & & 130.8 & 19.44 & 129. & 30.66 & \\
\hline $\begin{array}{l}\text { Diastolic blood } \\
\text { pressure }\end{array}$ & \multicolumn{2}{|c|}{$(\mathbf{n}=199)$} & \multicolumn{2}{|c|}{$(n=144)$} & \multicolumn{2}{|c|}{$(\mathbf{n}=\mathbf{5 5})$} & \\
\hline Min. - Max. & \multirow{2}{*}{\multicolumn{2}{|c|}{$\begin{array}{c}40.0-120.0 \\
80.85 \pm 13.06\end{array}$}} & \multirow{2}{*}{\multicolumn{2}{|c|}{$\begin{array}{c}60.0-120.0 \\
8189+1152\end{array}$}} & \multirow{2}{*}{\multicolumn{2}{|c|}{$\frac{40.0-100.0}{78.18 \pm 16.23}$}} & \\
\hline Mean \pm SD. & & & & & & & $>0.05$ \\
\hline \multicolumn{8}{|l|}{ Cr before } \\
\hline Min. - Max. & \multirow{2}{*}{\multicolumn{2}{|c|}{$\begin{array}{l}0.50-1.50 \\
1.01+0.22\end{array}$}} & \multicolumn{2}{|c|}{$0.50-1.50$} & \multicolumn{2}{|c|}{$0.60-1.50$} & \multirow{2}{*}{$<0.001$} \\
\hline Mean \pm SD. & & & 0.97 & 0.21 & 1.1 & $=0.23$ & \\
\hline GFR before & & & & & & & \\
\hline Min. - Max. & 26.0 & 202.0 & 26.0 & 202.0 & 42.0 & 163.0 & 0001 \\
\hline Mean \pm SD & 82.50 & 22.51 & 85.31 & 22.33 & 75.2 & $=21.52$ & \\
\hline $\begin{array}{c}\text { Cr after } \\
\text { Min. - Max. } \\
\text { Mean } \pm \text { SD. }\end{array}$ & $\begin{array}{r}0.70 \\
1.36 \\
\end{array}$ & $\begin{array}{l}4.0 \\
0.59 \\
\end{array}$ & $\begin{array}{l}0.70 \\
1.09 \\
\end{array}$ & $\begin{array}{l}1.90 \\
0.21 \\
\end{array}$ & $\begin{array}{r}1 \\
2.0 \\
\end{array}$ & $\begin{array}{l}4.0 \\
=0.66 \\
\end{array}$ & $<0.001$ \\
\hline GFR after & & & & & & & \\
\hline Min. - Max. & 13.0 & 137.0 & 16.0 & 137.0 & 13.0 & 128.0 & $<0.001$ \\
\hline Mean \pm SD & 60.90 & 25.05 & 70.22 & 20.62 & 36.9 & $=18.78$ & \\
\hline HF before & & & & & & & \\
\hline No & 156 & 78.0 & 130 & 90.3 & 26 & 46.4 & 001 \\
\hline Yes & 44 & 22.0 & 14 & 9.7 & 30 & 53.6 & 0.001 \\
\hline
\end{tabular}

TIMI flow before score was zero $33.9 \%$, one $3.6 \%$, two $7.1 \%$ and three $55.4 \%$ in the CIN positive group and was zero $28.5 \%$, one $1.4 \%$, two $7.6 \%$ and three $62.5 \%$ in the CIN negative group with no statistically significant difference. There was no statistically significant difference between the two groups as regards Contrast dose (ML), GPIIB IIIa inhibitors use and Stent implantation. The two groups showed no statistically significant difference as regards diseased artery (Culpirt) (Table 3). 
Table (3): Angiographic findings in the two studied groups

\begin{tabular}{|c|c|c|c|c|c|c|c|}
\hline \multirow{3}{*}{ Parameters Groups } & \multirow{2}{*}{\multicolumn{2}{|c|}{$\begin{array}{c}\text { Total } \\
(\mathbf{n}=\mathbf{2 0 0})\end{array}$}} & \multicolumn{4}{|c|}{ CIN } & \multirow{3}{*}{$\mathbf{P}$} \\
\hline & & & \multicolumn{2}{|c|}{ No $(n=144)$} & \multicolumn{2}{|c|}{ Yes $(n=56)$} & \\
\hline & No. & $\%$ & No. & $\%$ & No. & $\%$ & \\
\hline \multicolumn{8}{|c|}{ Diseased artery (CULPIRT) } \\
\hline LAD & 130 & 65.0 & 93 & 64.6 & 37 & 66.1 & $>0.05$ \\
\hline RCA & 73 & 36.5 & 54 & 37.5 & 19 & 33.9 & $>0.05$ \\
\hline LCX & 73 & 36.5 & 54 & 37.5 & 19 & 33.9 & $>0.05$ \\
\hline OM & 9 & 4.5 & 4 & 2.8 & 5 & 8.9 & $>0.05$ \\
\hline LM & 1 & 0.5 & 0 & 0.0 & 1 & 1.8 & $>0.05$ \\
\hline Ramus & 4 & 2.0 & 2 & 1.4 & 2 & 3.6 & $>0.05$ \\
\hline LIMA & 5 & 2.5 & 2 & 1.4 & 3 & 5.4 & $>0.05$ \\
\hline SVG & 1 & 0.5 & 0 & 0.0 & 1 & 1.8 & $>0.05$ \\
\hline \multicolumn{8}{|c|}{ Number of diseased vessels } \\
\hline Single & 70 & 35.0 & 54 & 37.5 & 16 & 28.6 & \multirow{2}{*}{$>0.05$} \\
\hline Multiple & 130 & 65.0 & 90 & 62.5 & 40 & 71.4 & \\
\hline \multicolumn{8}{|c|}{ TIMI flow before } \\
\hline No & 60 & 30.0 & 41 & 28.5 & 19 & 33.9 & \multirow{4}{*}{$>0.05$} \\
\hline I & 4 & 2.0 & 2 & 1.4 & 2 & 3.6 & \\
\hline II & 15 & 7.5 & 11 & 7.6 & 4 & 7.1 & \\
\hline III & 121 & 60.5 & 90 & 62.5 & 31 & 55.4 & \\
\hline Predilation & 124 & 62.0 & 82 & 56.9 & 42 & 75.0 & $<0.05$ \\
\hline \multicolumn{8}{|l|}{ Stent implantation } \\
\hline 1 & 109 & 54.5 & 83 & 57.6 & 26 & 46.4 & \multirow{3}{*}{$>0.05$} \\
\hline 2 & 76 & 38.0 & 52 & 36.1 & 24 & 42.9 & \\
\hline 3 & 15 & 7.5 & 9 & 6.3 & 6 & 10.7 & \\
\hline \multicolumn{8}{|l|}{ TIMI flow after } \\
\hline II & 22 & 11.0 & 11 & 7.6 & 11 & 19.6 & \multirow{2}{*}{$<0.05$} \\
\hline III & 178 & 89.0 & 133 & 92.4 & 45 & 80.4 & \\
\hline \multicolumn{8}{|c|}{ GPIIB IIIa inhibitors use } \\
\hline 0 & 157 & 78.5 & 114 & 79.2 & 43 & 76.8 & \multirow{2}{*}{$>0.05$} \\
\hline 1 & 43 & 21.5 & 30 & 20.8 & 13 & 23.2 & \\
\hline $\begin{array}{c}\text { Contrast dose (ML) } \\
\text { Min-Max } \\
\text { Mean } \pm \text { SD }\end{array}$ & \multicolumn{2}{|c|}{$\begin{array}{c}120.0-290.0 \\
192.1 \pm 32.18\end{array}$} & \multicolumn{2}{|c|}{$\begin{array}{c}120.0-290.0 \\
191.8 \pm 35.33\end{array}$} & \multicolumn{2}{|c|}{$\begin{array}{l}120.0-230.0 \\
192.9 \pm 22.1\end{array}$} & $>0.05$ \\
\hline
\end{tabular}

ROC curve revealed that CHADSVASC score cutoff value is higher than 3 and the area under the ROC curve is equal to 0.906 which indicating that it is excellent predictor for contrast induced nephropathy cases. The sensitivity, Specificity, positive predictive value and negative predictive values of CHADSVASC score were 80.36, 89.58, 51.5, and 96.0 respectively (Figure 1). 


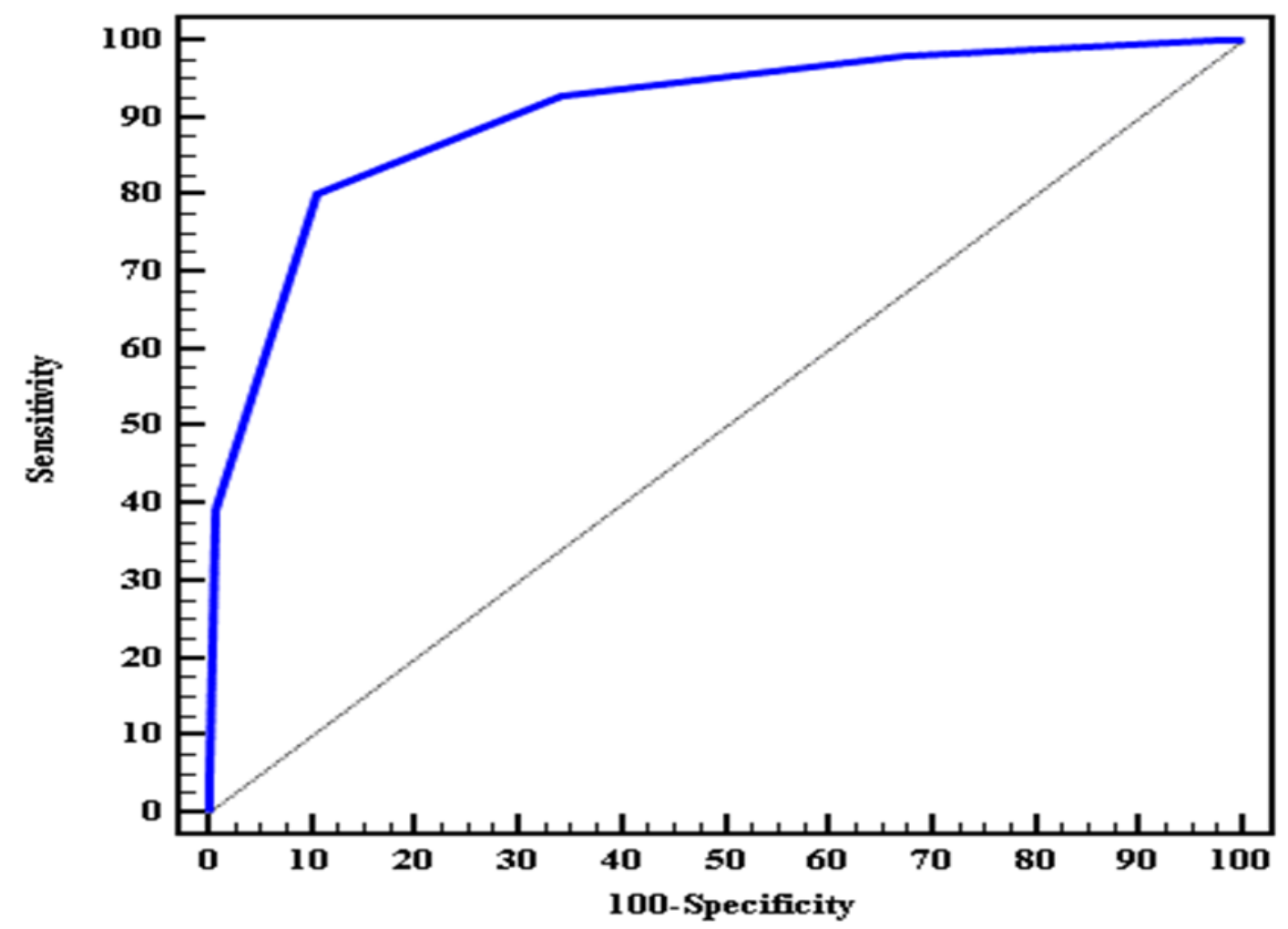

Figure (1): ROC curve for CHADSVASC score to predict CIN cases $(\mathbf{n}=\mathbf{5 6})$

\section{DISCUSSION}

The CVRS was traditionally used for embolic risk stratification in AF patients to provide further optimal anticoagulant therapy (Camm et al., 2012). Previous studies confirmed that CVRS could be used for the prediction of coronary artery disease and long-term clinical outcomes in patients undergoing PCI (Hunag et al., 2017). Moreover, it was feasible in predicting acute stent thrombosis in AFfree patients and the no-reflow phenomenon among patients with STEMI who underwent emergency PCI (Ipek et al., 2016).

Contrast-induced nephropathy (CIN) is defined as an absolute increase in serum creatinine by $\geq 0.3 \mathrm{mg} / \mathrm{dL}$ from base line or relative increase in serum creatinine by $\geq 50 \%$ from baseline within 48 hours after administrated of iodinated contrast material (Davenport et al., 2013).

An acute kidney injury that frequently occurs after administration of contrast media is a well-known complication of cardiac catheterization. The reported incidence of CIN varies widely in different populations, depending on the presence of risk factors. Its development has been associated with increased inhospital and long-term morbidity and mortality, prolonged hospitalization, and long-term renal impairment. The exact mechanisms of CIN are not clear and are thought to be multifactorial. Previous studies have shown that renal vasoconstriction, endothelial dysfunction, endothelial cell damage followed by renal tubular damage and medullary hypoxia are the various mechanisms responsible for contrast-induced renal injury. Female 
gender, older age, diabetes, hypertension, high central pulse pressure, $\mathrm{CHF}$, and renal dysfunction are well known risk factors for development of CIN (Caiazza et al., 2014). Patients with CHF are further at an increased risk for CIN as poor renal perfusion leads to a greater degree of renal vasoconstriction in adjunct with a low preload status in these subjects (Andareucci et al., 2014). Our study too demonstrated significant correlation between CIN and diabetes, hypertension, higher systolic blood pressure, $\mathrm{CHF}$ as evident from (i) a higher Killip class and (ii) a lower left ventricular systolic function, and pre-existing renal disease. Other predictors such as low hemoglobin and higher contrast volume were also found significantly correlated with risk of CIN, which are parts of Mehran risk model. Previously, CHADS2 and CHA2DS2-VASc scores were found to be associated with both short- and long-term adverse clinical outcomes and mortality in patients with stable $C A D$ and ACS. Uysal et al. (2016).

The study by Chou et al. (2016) demonstrated that CHADS2 score predicts the risk of CIN in patients with stable CAD undergoing elective PCI. However, in our study, we used the CHA2DS2VASc score instead of CHADS2 as it's a more comprehensive tool and had applied on patients with ACS and stable CAD. CHA2DS2-VASc score is a simpler risk score containing only pre procedural variables which makes it easy to compute and, hence, more practical.

In our study we found that The WMSI, The $\mathrm{Cr}$ before and HF before were statistically significant higher in the CIN positive group. The GFR before was statistically significant lower in the CIN positive group. The two groups showed no statistically significant difference as regards diseased artery (CULPIRT).

Our results were supported by study of Baydar and Kilic (2019) as they reported that left ventricular ejection fraction and eGFR were significantly lower in high score group.

Regarding Chaudhary et al. (2019) there was statistically significant difference among both studied groups as regard serum creatinine and number of vessels.

Our study showed that there was no statistically significant difference between the two groups as regards TIMI, Contrast dose (ML) and GPIIB IIIa inhibitors use. The $\mathrm{Cr}$ after was statistically significant higher in the CIN positive group. The GFR after was statistically significant lower in the CIN positive group. Predilatation was statistically significant increase in the CIN positive group. There was no statistically significant difference as regard Stent implantation. The need to fluids and diuretics was statistically significant higher in the CIN positive group. CHADSVASC score and in hospital stay were statistically significant higher in the CIN positive group.

Our results were supported by study of Salama et al. (2019) as they showed increasing creatinine level after primary PCI in which CHADS2-VASC score of the patient was higher compared to the other group in which CHADS2-VASC score was low. As regard hospital stay for the patients who were diagnosed with CIN post PPCI was more prolonged than of the patients who were not diagnosed with CIN with statistical significance relation 
between two study groups regarding inhospital stay ( $\mathrm{p}<0.001)$. In concordant to this study, Kurtul et al. (2017) showed increasing creatinine level in patients with high grade score.

In the present study, ROC results revealed that CHADSVASC score cutoff value was higher than 3 and the area under the ROC curve was equal to 0.906 which indicating that it is excellent predictor for contrast induced nephropathy cases.

Our results were supported by study of Kurtul et al. (2017) as they reported that receiver operating characteristic curve analysis revealed good diagnostic value of CHA2DS2-VASC score in predicting CIN and multivariate analysis identified the CHA2DS2-VASC score of $\geq 4$ as an independent predictor of CIN.

Salama et al. (2019) demonstrated that the CHA2DS2-VASC score $>3$ was independently associated with CIN development in patients with STEMI who were treated by PCI and the more CHADS2-VASC score, the more the incidence for developing CIN after PPCI.

Our study also were supported by Wang et al. (2019) as they reported that the receiver operating characteristic curve analysis showed a good diagnostic value of the CVRS in predicting CIN among patients with CTO who underwent interventional therapy for having CVRS $\geq 3$ Thus,CHA2DS2-VASc score due to its ease of usage permits us to predict the occurrence of CIN in patients with ACS and implement prophylactic measures (intravenous hydration) before contrast exposure to prevent CIN (Chong et al., 2015).

\section{CONCLUSION}

CHA2DS2-VASc score serves as a simple yet effective tool for predicting CIN pre procedure, which can be easily implemented in day-to-day clinical practice.

The present study demonstrated that the CHA2DS2-VASC score >3 was independently associated with CIN development in patients with IHD who were treated by PCI. The more CHADS2VASC score, the more risk for developing CIN after PCI, Thus CVRS can be used as a simple pre-procedural predictor of CIN among patients with IHD undergoing PCI.

\section{REFERENCES}

1. AndreucciM, Solomon $R$ and Tasanarong A (2014): Side effects of radiographic contrastmedia: pathogenesis, risk factors, and prevention. Bio Med Res Int., 11:741018.

2. Baydar $O$ and Kilic A. (2019): CHA2DS2-VASC Score Predicts Risk of Contrast-Induced Nephropathy in NonST Elevation Myocardial Infarction Patients Undergoing Percutaneous Coronary Interventions. Kidney Diseases, 5(4): 266-271.

3. Bozbay M, Uyarel $\mathbf{H}$ and Cicek $\mathbf{G}$ (2017): CHA2DS2-VASc Score Predicts In-Hospital and Long-Term Clinical Outcomes in Patients With ST-Segment Elevation Myocardial Infarction Who Were Undergoing Primary Percutaneous Coronary Intervention. Clin Appl Thromb Hemost., 23(2): 132-138.

4. Brar SS, Shen AY and Jorgensen MB (2018): Sodium bicarbonate vs sodium chloride for the prevention of contrast medium-induced nephropathy in patients undergoing coronary angiography: a randomized trial. JAMA, 300(9):10381046. 
5. Caiazza A, Russo $L$ and Sabbatini $M$ (2014): Hemodynamic and tubular changes induced by contrast media. BioMed Res Int., 21:578974.

6. Camm AJ, Lip GY, De Caterina R and Savelieva (2012): I ESC Committee for practice guidelines (CPG). 2012 focused update of the ESC guidelines for the management of atrial fibrillation: an update of the 2010 ESC guidelines for the management of atrial fibrillation. Developed with the special contribution of the European heart rhythm association. Eur Heart J, 33(21):2719-47.

7. Chaudhary A. K., Pathak V., Kunal S., Shukla $S$ and Pathak P. (2019): CHA2DS2-VASc score as a novel predictor for contrast-induced nephropathy after percutaneous coronary intervention in acute coronary syndrome. Indian Heart Journal, 71(4):303-308.

8. Chong E, Poh KK and Lu Q (2015): Comparison of combination therapy of high-dose oral $\mathrm{N}$-acetylcysteine and intravenous sodium bicarbonate hydration with individual therapies in the reduction of Contrast-induced Nephropathy during Cardiac Catheterisation and Percutaneous Coronary Intervention (CONTRAST):a multi-centre, randomised, controlled trial. Int J Cardiol., 201:237e242.

9. Chou RH, Huang PH and Hsu CY (2016): CHADS2 score predicts risk of contrast induced nephropathy in stable coronary artery disease patients undergoing percutaneous coronary interventions. J Formos Med Assoc., 115:501e509.

10. Davenport M.S, Khalatbari S, Cohan R.H, Dillman J .R, Myles J.D and Ellis J.H (2013): contrast material-induced nephrotoxicity and intravenous low osmolarity iodinated contrast material: Risk stratification by using estimated glomerular filtration rate, Radiology, 268(3):719-728.

11. Huang FY, Huang BT and Pu XB (2017): CHADS2, CHA2DS2-VASc and R2CHADS2 scores predict mortality in patients with coronary artery disease. Intern Emerg Med., 12(4):479-86.

12. Hudzik B, Szkodziński J, Hawranek $M$, Lekston A, Poloński $L$ and Gąsior $M$ (2016): CHA2DS2-VASc score is useful in predicting poor 12-month outcomes following myocardial infarction in diabetic patients without atrial fibrillation. Acta Diabetol., 53(5):807-815.

13. Ipek G, Onuk $T$ and Karatas $M B$ (2016): CHA2DS2-VASc score is a predictor of no reflow in patients with ST-segment elevation myocardial infarction who underwent primary percutaneous intervention. Angiology, 67(9):840-5.

14. Kurtul A, Yarlioglues $M$ and Duran M. (2017): Predictive value of CHA2DS2-VASC scores for contrastinduced nephropathy after percutaneous coronary intervention for acute coronary syndrome. Am J Cardiol., 119:819-825.

15. Levey AS, Stevens LA, Schmid CH, Zhang YL and Castro AF (2011): A new equation to estimate glomerular filtration rate. Ann Intern Med., 150(9):604-612.

16. Lip GYH, Nieuwlaat $R$ and Pisters $R$ (2010): Refining clinical risk stratification for predicting stroke and thromboembolism in atrial fibrillation using a novel risk factor-based approach: the euro heart survey on atrial fibrillation. Chest, 137(2): 263-272.

17. Liu FD, Shen XL and Zhao R (2016): Predictive role of CHADS2 and CHA2DS2-VASc scores on stroke and thromboembolism in patients without 
atrial fibrillation: a meta-analysis. Ann Med., 48(5): 367-375.

18. Paoletti Perini A, Bartolini $S$ and Pieragnoli $P$ (2014): CHADS2 and CHA2DS2-VASc scores to predict morbidity and mortality in heart failure patients candidates to cardiac resynchronization therapy. Europace, 16(1): 71-80.

19. Salama M. M., Ahmed F. and Mohamed N. H. (2019): CHADS2VASC Score as a Predictor for Contrast Induced Nephropathy in Patient with Acute Myocardial Infarction Treated with Primary Percutaneous Coronary Intervention. The Medical Journal of Cairo University, 87(9):3247-3255.
20. Uysal OK, Turkoglu $C$ and Duran $M$ (2016): Predictive value of newly defined CHA2DS2-VASc-HSF scores for severity of coronary artery disease in STEMI. Cardiol Pol., 74:954e960.

21. Wang, Y., Zhao, H. W., Zhang, X. J., Chen, B. J., Yu, G. N., Hou, A. J. and Luan, B. (2019): CHA2DS2-VASC score as a preprocedural predictor of contrast-induced nephropathy among patients with chronic total occlusion undergoing percutaneous coronary intervention: a single-center experience. BMC Cardiovascular Disorders, 19(1): $74-86$. 


\section{معامل اتشاد فاسك كمتنبئ لحدوث إعتلال كلوي نتيجة استعمال

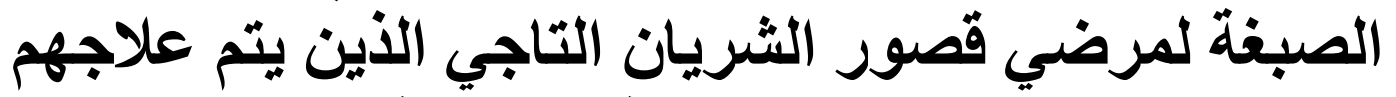 بالقسطرة القلبية التداخلية التئية}

إسلام شحاته عبداللاه، أسامة احمد خميس*، مصطقي عطية السواساني، إبراهيم فرج الله سعيد

قسمي القلب والباطنه*، كلية الطب، جامعة الازهر ، القاهرة

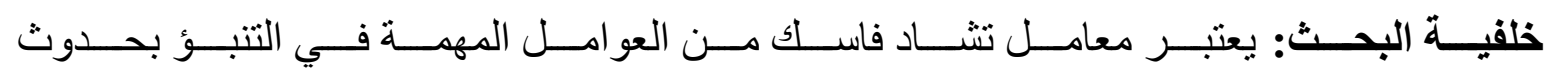

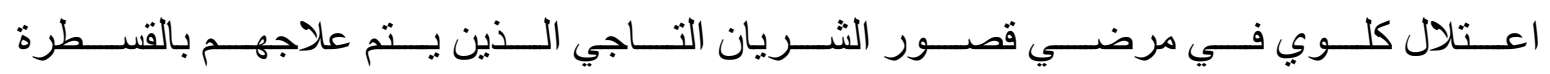

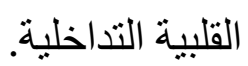

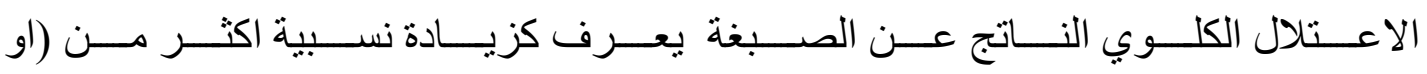

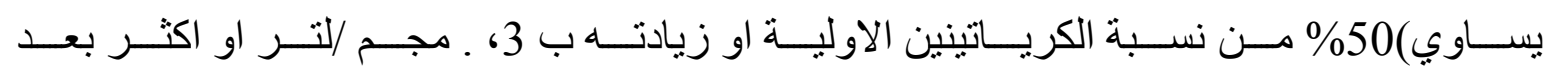
48 ساعة من اجر اء القسطرة.

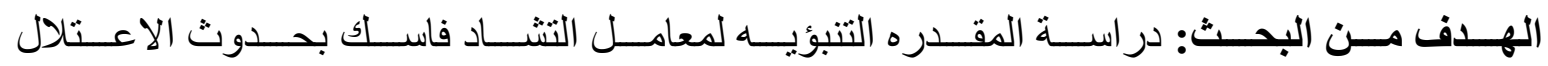

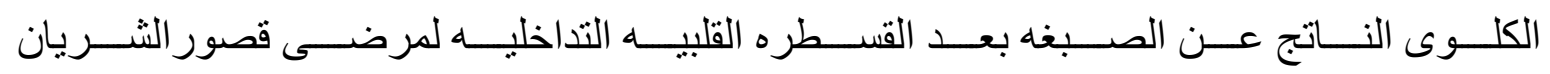
التاجي.

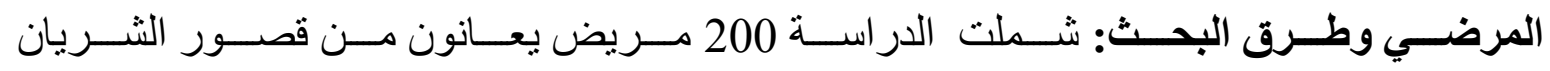

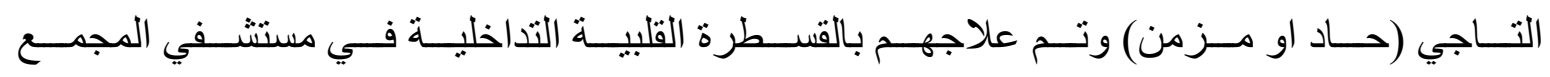
الطبي النموذجي بطنطا من يناير 2019 حتي نهاية يناير 2020 وناد

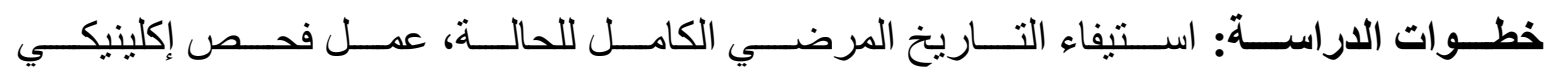

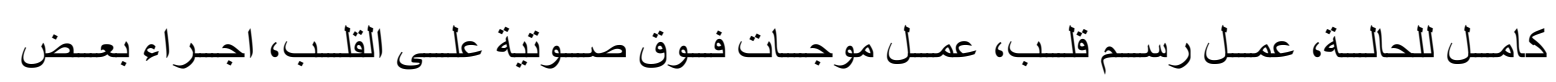

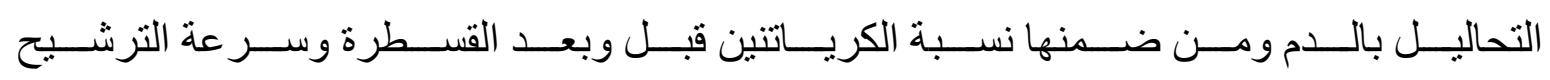

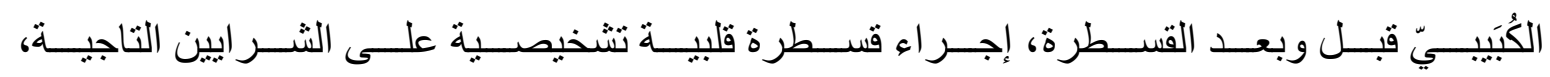

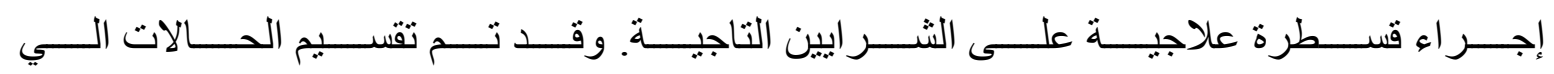

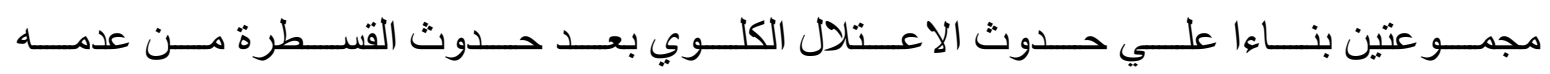

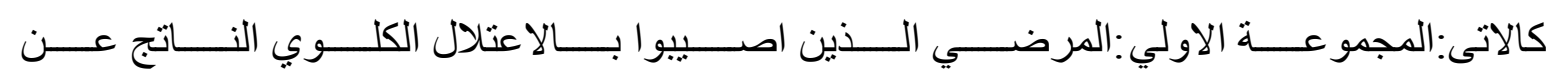




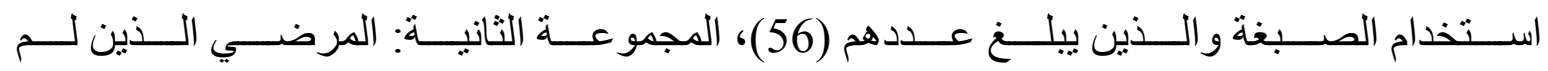

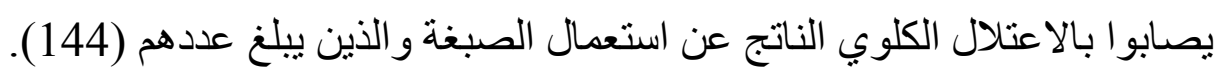

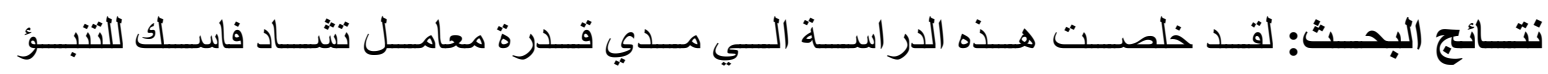

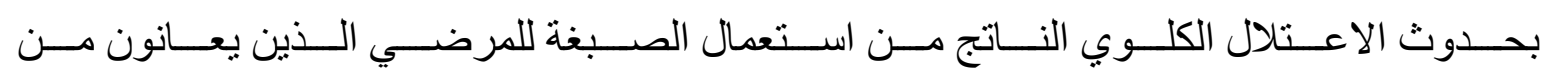

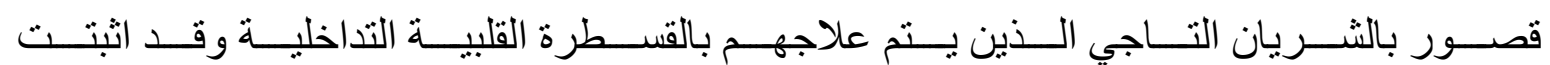

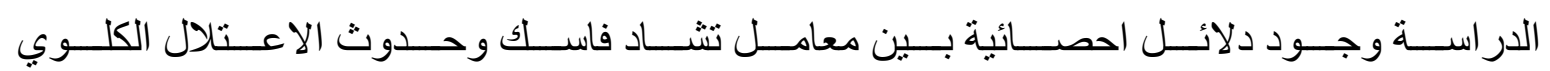

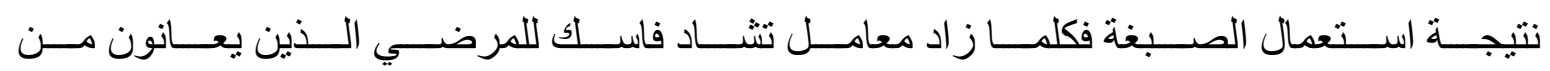

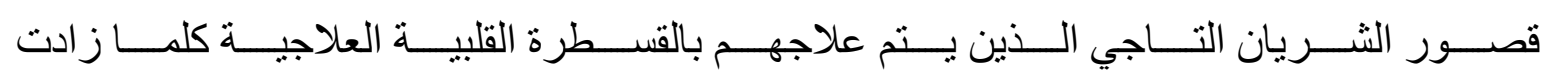
نسبة حدوث الاعتلال الكلوي.

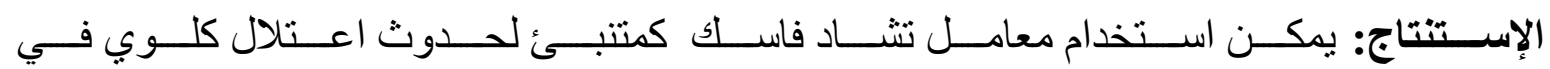

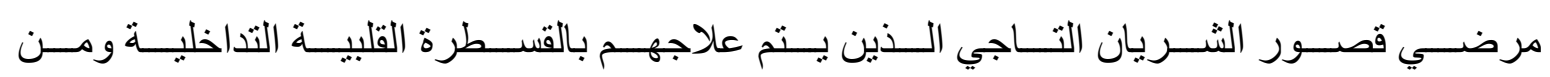
ثم أخذ التدابير اللازمة للحد من حدوث اعنلال كلوي ناتج عن استخدام الصبغة. 